\title{
MATURAÇÃO FISIOLÓGICA DE SEMENTES DE MAXIXE (Cucumis anguria L.) ${ }^{1}$
}

\author{
MARIA APARECIDA DE MEDEIROS², LEILSON COSTA GRANGEIRO³, \\ SALVADOR BARROS TORRES ${ }^{4}$, ANA VALERIA LACERDA FREITAS ${ }^{5}$
}

\begin{abstract}
RESUMO - Objetivou-se com esse trabalho avaliar as modificações físicas e fisiológicas das sementes de maxixe durante o processo de maturação, as quais são aspectos importantes no que diz respeito à obtenção de sementes de alta qualidade e minimização de sua deterioração no campo. As sementes foram colhidas de frutos da cultivar do Norte, em intervalos de cinco dias, do $15^{\circ}$ ao $40^{\circ}$ dia após a antese (DAA). O delineamento experimental utilizado foi o inteiramente casualizado, com seis tratamentos $(15,20,25,30,35$ e 40 DAA) e quatro repetições. Para cada época, os frutos foram avaliados visualmente e determinado o peso médio, e as sementes extraídas dos frutos foram avaliadas pelos seguintes testes e/ou determinações: teor de água, massa da matéria seca das sementes, germinação, primeira contagem, condutividade elétrica, envelhecimento acelerado e índice de velocidade de emergência. As sementes atingiram a maturidade fisiológica aos 32 dias após DAA, embora a melhor época para realizar a colheita de frutos seja no período de 35 a 40 DAA, quando as sementes se encontram com menor teor de água.
\end{abstract}

Termos para indexação: Cucumis anguria, qualidade fisiológica, germinação.

PHYSIOLOGICAL MATURITY IN GHERKIN (Cucumis anguria L.) SEEDS

\begin{abstract}
The objective of this study was to evaluate the physical and physiological changes in the maturation of gherkin (Cucumis anguria L.) seeds since these aspects are important for high quality seed production and reducing seed deterioration in the field. Seeds were collected from fruits of the Norte cultivar at five-day intervals from the 15th to the 40th day after anthesis. The statistical design was completely randomized with six treatments (fruit ages) and four replications. For each fruit age, the fruits were evaluated visually and the mean weight determined. The seeds were evaluated regarding: moisture content, seed dry mass, germination, first count of ermination, electrical conductivity, accelerated aging, and emergence speed index. The maximum physiological quality was found in seeds collected 32 days after anthesis but the best time to harvest the fruits was from 35 to 40 days after anthesis when the seeds showed the lowest moisture content.
\end{abstract}

Index terms: Cucumis anguria, physiological quality, germination.

\footnotetext{
${ }^{1}$ Submetido em 30/06/2009. Aceito para publicação em 19/03/2010. Parte da dissertação de mestrado do primeiro autor apresentada à Universidade Federal Rural do Semi-Árido (UFRSA).
}

${ }^{2}$ Eng. Agr., Mestre em Agronomia, doutoranda do Programa de Pósgraduação em Agronomia, UFERSA. E-mail: aparecidacn@gmail.com.

${ }^{3}$ Eng. Agr., Dr., Prof. Adjunto, Dept. de Ciências Vegetais, UFERSA, Caixa
Postal 137, CEP 59625-900. Mossoró, RN. E-mail: leilson@ufersa.edu.br.

${ }^{4}$ Eng. Agr., Dr., Pesquisador da Empresa de Pesquisa Agropecuária do Rio Grande do Norte (EMPARN) e Prof. Colaborador do Departamento de Ciências Vegetais, UFERSA. E-mail: sbtorres@ufersa.edu.br.

${ }^{5}$ Eng. Agr., doutoranda do Programa de Pós-graduação em Agronomia, UFERSA. E-mail: anavalerialf@yahoo.com.br 


\section{INTRODUÇÃO}

O baixo desempenho da cultura do maxixe no Brasil deve-se em parte à diversidade genética do material cultivado, do qual se obtém em consequência grande desuniformidade na produção de frutos, em termos qualitativos e quantitativos, e sementes de baixa qualidade, principalmente no que diz respeito à qualidade fisiológica.

De forma geral, os produtores de maxixe utilizam sementes locais obtidas de plantas espontâneas que aparecem nos cultivos tradicionais como feijão, milho e hortas domésticas. Como essas sementes são produzidas sem nenhum manejo, sua qualidade fisiológica é normalmente baixa. Além disso, poucos estudos foram realizados no que diz respeito aos aspectos agronômicos do maxixe, portanto, a produção de semente comercial desta cultura é pequena.

A maturidade fisiológica da semente e o momento ideal de sua colheita estão intimamente relacionados, promovendo a preservação da qualidade fisiológica da semente após a colheita. Contudo, a obtenção de lotes de sementes com elevada qualidade depende da identificação precisa do momento ideal da colheita, o qual corresponde frequentemente à época em que a maturidade fisiológica é atingida, coincidindo também com o momento de máximo acúmulo de massa seca, elevado vigor e alta germinabilidade potencial (Carvalho e Nakagawa, 2000).

Como o desenvolvimento da semente é normalmente acompanhado pelo desenvolvimento do fruto, diversos marcadores têm sido empregados para a determinação da maturidade fisiológica das sementes, dentre eles a mudança de coloração dos frutos, o tamanho dos frutos, o peso das sementes e o teor de água. A desuniformidade na coloração dos frutos de maxixe ao longo do ciclo da cultura, mesmo quando se utiliza material "melhorado", tem tornado difícil estimar o momento ideal de maturação das sementes.

Dessa forma, considerando os fatos acima mencionados e a ausência de informações sobre a maturidade fisiológica de sementes de maxixe, objetivou-se com este trabalho avaliar as modificações físicas e fisiológicas destas sementes durante o processo de maturação.

\section{MATERIAL E MÉTODOS}

O campo de produção das sementes foi instalado na Horta Didática do Departamento de Ciências Vegetais da Universidade Federal Rural do Semi-Árido, em MossoróRN, no período de dezembro de 2007 a março de 2008, em solo classificado como Argissolo Vermelho-Amarelo. Da área experimental foram retiradas amostras de solo, cuja análise química, revelou os seguintes resultados: $\mathrm{pH}$ (água) $=7,4 ; \mathrm{P}=$ $281,97 \mathrm{mg} \cdot \mathrm{dm}^{-3} ; \mathrm{K}=0,3 \mathrm{cmolc} \cdot \mathrm{dm}^{-3} ; \mathrm{Ca}=6,4 \mathrm{cmolc} \cdot \mathrm{dm}^{-3}, \mathrm{Na}$ $=0,44 \mathrm{cmolc} \cdot \mathrm{dm}^{-3}$ e $\mathrm{Mg}=3,1 \mathrm{cmolc} \cdot \mathrm{dm}^{-3}$.

No preparo do solo, foram realizadas aração e gradagem seguida de sulcamento e adubação de plantio com base na análise de solo, colocando-se $40 \mathrm{~kg} \cdot \mathrm{ha}^{-1} \mathrm{de} \mathrm{N}, 80 \mathrm{~kg} \cdot \mathrm{ha}^{-1}$ de $\mathrm{P}_{2} \mathrm{O}_{5}$ e $40 \mathrm{~kg} \cdot \mathrm{ha}^{-1}$ de $\mathrm{K}_{2} \mathrm{O}$, respectivamente, na forma de ureia, superfosfato simples e cloreto de potássio. A irrigação foi aplicada por gotejamento com emissores de 1,6 L.h. ${ }^{-1}$, com frequência de rega diária.

As sementes demaxixe, cultivarDo Norte, foram semeadas no espaçamento de $1,0 \mathrm{~m} \times 0,3 \mathrm{~m}$, colocando-se três sementes por cova e, aos dez dias após o plantio, realizou-se o desbaste, deixando-se uma planta por cova. As demais práticas culturais obedeceram às necessidades da cultura. Durante o ciclo da cultura, as flores foram etiquetadas no dia de sua antese, pela manhã, e as colheitas dos frutos realizadas em conformidade com as idades pré-estabelecidas para os tratamentos, isto é, 15, 20, 25, 30, 35 e 40 dias após a antese (DAA).

Depois de colhidos, os frutos foram levados ao Laboratório de Análise de Sementes, onde foram registrados seus aspectos visuais através de fotos e, também, determinado o peso médio do fruto (g.fruto ${ }^{-1}$ ) através de duas repetições de 10 frutos. Em seguida, as sementes foram imediatamente extraídas, lavadas e submetidas à assepsia com solução de hipoclorito de sódio a $10 \%$ por dez minutos e secadas à temperatura ambiente de laboratório por 48 horas. A qualidade das sementes foi avaliada pelos seguintes testes e/ ou determinações:

Teor de água - realizado com duas subamostras de 0,5 gramas de sementes por tratamento, pelo método estufa $105 \pm 3{ }^{\circ} \mathrm{C}$, durante 24 horas, de acordo com as Regras para Análise de Sementes - RAS (Brasil, 1992) e os resultados expressos em porcentagem.

Peso da matéria seca das sementes - determinado em duas repetições de 30 sementes com base no resultado final das sementes após secagem a $105 \pm 3{ }^{\circ} \mathrm{C}$, durante 24 horas (Brasil, 1992), sendo os resultados expressos em g.30 sementes ${ }^{-1}$.

Germinação - conduzido com quatro repetições de 50 sementes, distribuídas sobre duas folhas de papel mata-borrão umedecidas com água equivalente a 2,5 vezes o peso do substratoseco,acondicionadasem caixas plásticas transparentes $(11,5 \mathrm{~cm} \times 11,5 \mathrm{~cm} \times 3,5 \mathrm{~cm})$ e mantidas em germinador sob temperatura alternada de $20-30{ }^{\circ} \mathrm{C}$ e fotoperíodo de oito horas na maior temperatura. As avaliações foram realizadas aos quatro e oito dias após a semeadura, determinando-se a percentagem de plântulas normais (Brasil, 1992).

Primeira contagem da germinação - realizada em 
conjunto com o teste de germinação, determinando-se a porcentagem de plântulas normais no quarto dia após a semeadura (Brasil, 1992).

Condutividade elétrica - utilizaram-se quatro repetições de 25 sementes, que foram pesadas e colocadas para embeber em copos plásticos contendo $25 \mathrm{~mL}$ de água destilada e mantidas em incubadora BOD a $30{ }^{\circ} \mathrm{C}$ por quatro horas (Torres et al., 1998). As leituras foram feitas em condutivímetro e os resultados expressos em $\mu \mathrm{S} . \mathrm{cm}^{-1} \cdot \mathrm{g}^{-1}$ de sementes.

Envelhecimento acelerado - adotou-se a metodologia recomendada pela AOSA (1983) e complementada por Marcos Filho (1999). Foram utilizadas caixas de plástico para germinação $(11,5 \mathrm{~cm} \times 11,5 \mathrm{~cm} \times 3,5)$, possuindo em seu interior uma bandeja com tela de alumínio onde as sementes, em torno de 250, foram distribuídas de maneira a formar uma camada uniforme. Dentro de cada caixa foram adicionados $40 \mathrm{~mL}$ de água destilada. As caixas tampadas permaneceram no interior da câmara, a $41{ }^{\circ} \mathrm{C}$, por 72 horas (Torres e Marcos Filho, 2001). Decorrido este período, as sementes foram submetidas ao teste de germinação, conforme metodologia descrita para este teste.

Índice de velocidade de emergência de plântulas (IVE) - quatro repetições de 50 sementes foram semeadas a $0,5 \mathrm{~cm}$ de profundidade em bandejas plásticas contendo areia lavada e esterilizada e umedecida a $60 \%$ da capacidade de retenção. As bandejas foram mantidas em laboratório à temperatura média de $28{ }^{\circ} \mathrm{C}$, sendo feitas contagens diárias do número de plântulas emersas até o décimo dia (Maguire, 1962).

Procedimento estatístico - o delineamento experimental utilizado foi o inteiramente casualizado, com seis tratamentos $(15,20,25,30,35$ e 40 dias DAA) e quatro repetições. Todas as variáveis analisadas, exceto a coloração dos frutos, foram submetidas à análise de regressão e ajustes de curvas em função da idade dos frutos com auxílio do software Table Curve (Jandel, 1991).

\section{RESULTADOS E DISCUSSÃO}

A coloração dos frutos variou com a idade de colheita, completamente verdes aos 15 DAA; início de amarelamento aos 20 DAA, com intensificação aos 25 DAA; predominantemente amarelados a partir dos 30 DAA (Figura 1). A identificação visual da maturidade fisiológica contribui para detectar a época em que as sementes apresentam a máxima qualidade ou se encontram muito próxima desse nível (Marcos Filho, 2005). Comercialmente os frutos de maxixe tem mercado quando colhidos até 20 DAA, pois o consumo deste fruto é realizado quando os frutos ainda se encontram verdes e tenros, momento este em que as sementes se encontram brandas, tornando-se agradáveis ao paladar.

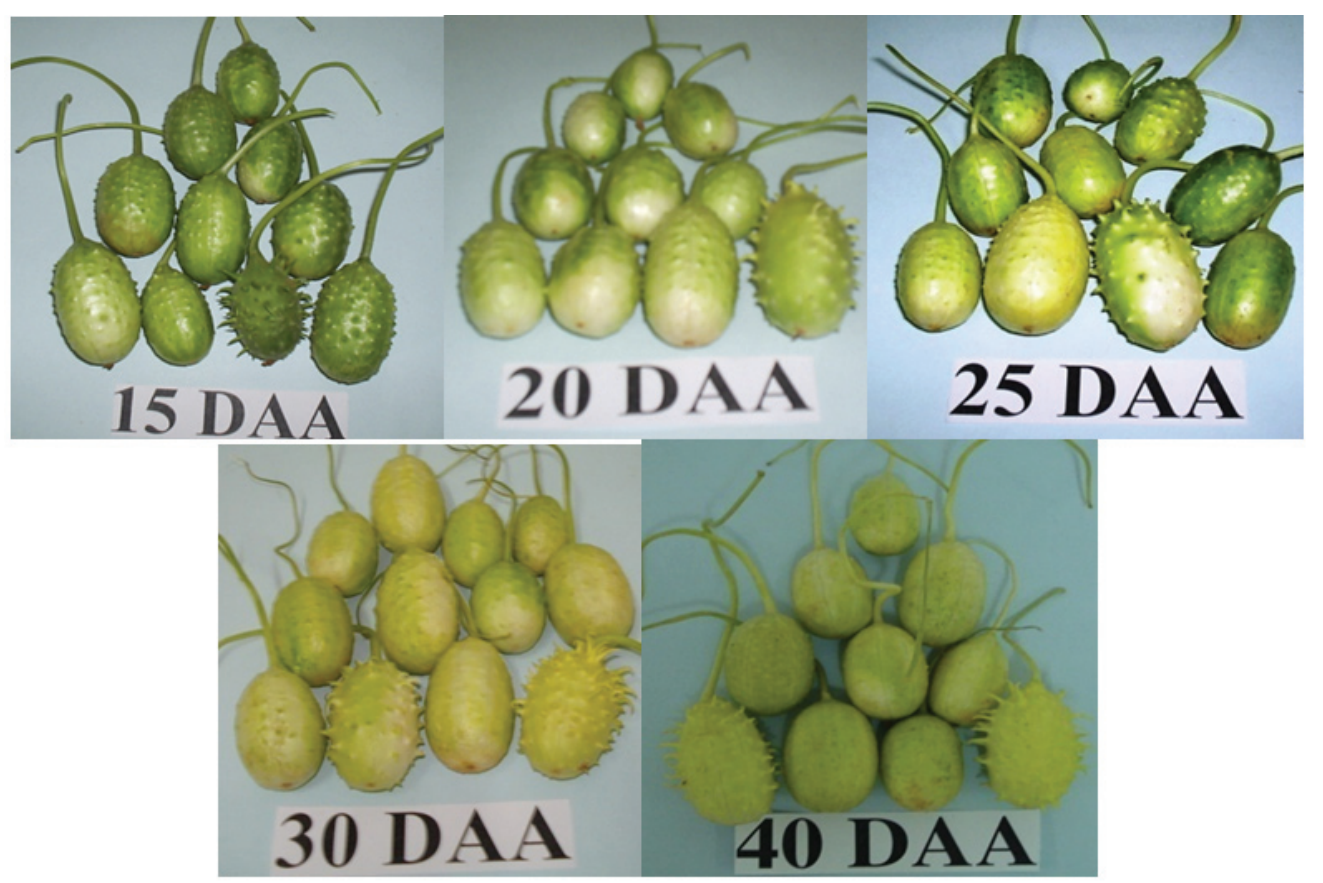

FIGURA 1. Variação da coloração dos frutos de maxixe, cultivar Do Norte, em função da idade (15, 20, 25, 30 e 40 dias após a antese (DAA). 
A massa média dos frutos variou de $15,81 \mathrm{~g}$ aos 15 DAA a 22,63 g aos 40 DAA, ou seja, aumentou gradativamente ao longo de todo o período de desenvolvimento dos frutos (Figura 2A). Na fase inicial de crescimento dos frutos, o acúmulo de massa seca foi pequeno, tendo se intensificado a partir dos 20 até 35 DAA, período em que ocorreu um incremento médio de $32 \%$, contrariamente ao período final, em que os frutos apresentaram um menor acúmulo de massa seca,
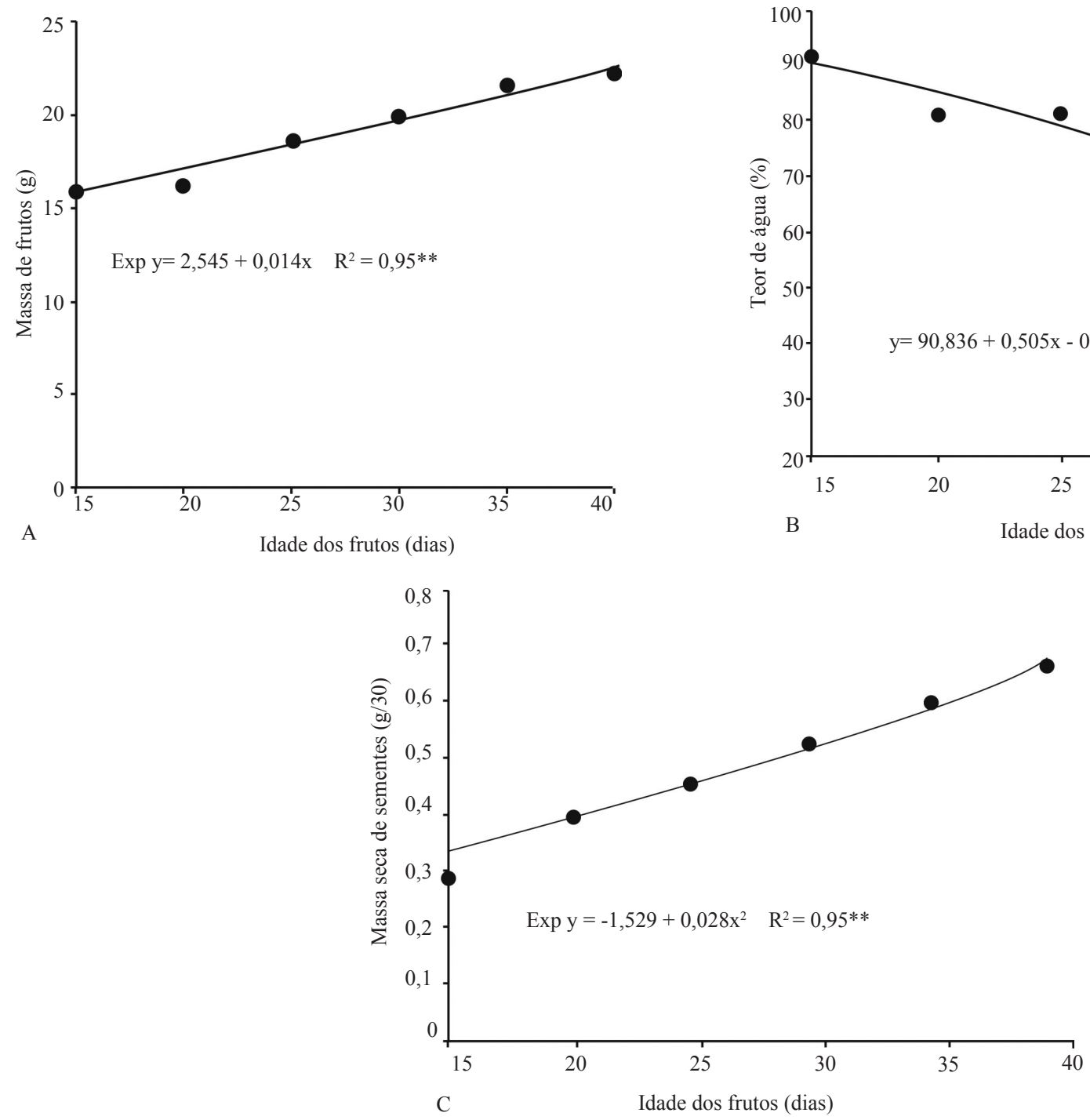

FIGURA 2. Massa de frutos g (A), teor de água das sementes \% (B) e massa seca das sementes g (C) de maxixe, cv Do Norte, em função da idade dos frutos.

O teor de água das sementes decresceu à medida que aumentou a idade dos frutos (Figura 2B). Esse decréscimo foi contínuo durante todo o período analisado, sendo que aos 15 DAA as sementes se encontravam com teor de água de $89,9 \%$ e aos 40 DAA decresceu para $50,56 \%$. Houve intensificação de desidratação a partir dos 25 DAA, com incremento médio de $8 \%$. Conforme Gillaspy et al. (1993), a fase de crescimento acelerado corresponde ao estádio no qual há elevada frequência de divisões celulares, ao qual segue o estádio em que predomina a expansão celular e daí o estádio de amadurecimento. Comportamento semelhante foi observado em outras cucurbitáceas como abóbora (Medeiros, 2006; Vidigal et al., 2007), melancia (Grangeiro et al., 2005) e melão (Villanueva et al., 2000; Giehl et al., 2008).

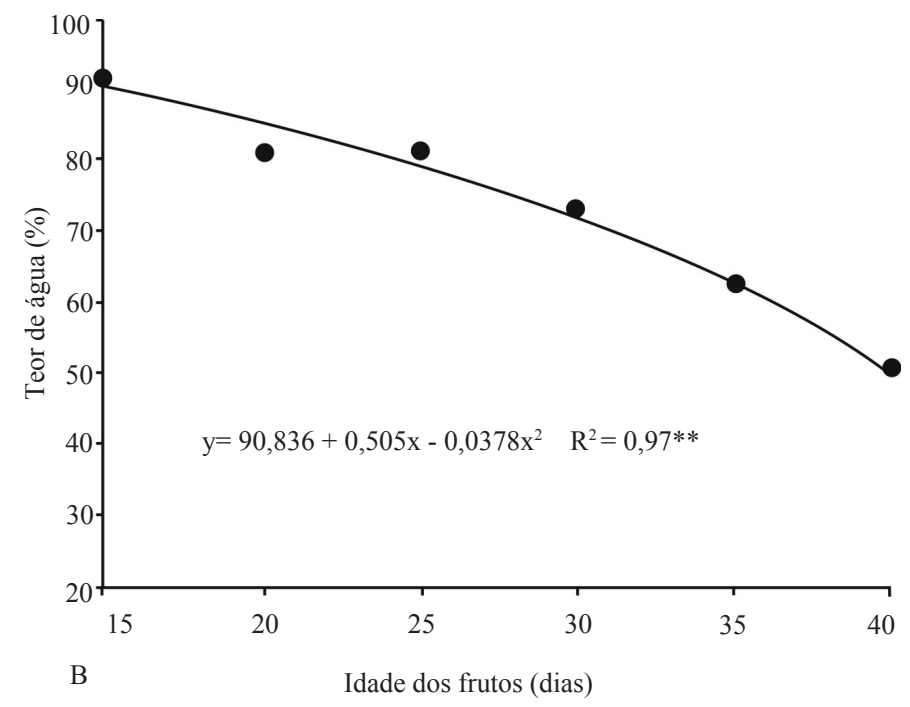

embora as sementes tenham chegado ao final do período observado com o teor de água ainda elevado. Isso pode ter ocorrido por se tratar de frutos carnosos com alto teor de água, o que também foi observado por outros autores em frutos de abóbora italiana (Alvarenga et al., 1991), pimenta (Vidigal et al., 2009a,b) e tomate (Vidigal et al.,

\footnotetext{
Revista Brasileira de Sementes, vol. $32, n^{\circ} 3$ p. 017-024, 2010
} 
2006). Segundo Welbaum e Bradford (1988), embora seja utilizado, o teor de água das sementes não é um indicador adequado de maturidade fisiológica, por sofrer influências ambientais e genéticas.

A massa seca das sementes foi crescente até os 40 DAA (Figura 2C), sendo que o maior incremento foi verificado entre os 25 e 35 DAA, momento este coincidente com o período de maior redução no teor de água nas sementes (Figura 2B), sendo um provável indicativo da maturidade fisiológica. O início do desenvolvimento da semente é caracterizado pelo acúmulo relativamente lento de massa seca (Figura 2C), pois é nesta fase que predominam a divisão e a expansão celulares, responsáveis pela constituição da estrutura adequada para receber as substâncias transferidas da planta-mãe. A fase seguinte é caracterizada pelo fluxo de acúmulo de massa seca que se intensifica até atingir seu máximo, o que ocorre quando a semente ainda apresenta teor de água relativamente elevado (Marcos Filho, 2005). Nesse sentido, Costa et al. (2006) constataram, em frutos de abóbora híbrida, que as sementes ganham massa até os 50 DAA, ocorrendo estabilização a partir deste ponto.

O percentual de germinação aumentou gradativamente, sendo observado o maior valor aos 30DAAde $89,55 \%$ (Figura $3 \mathrm{~A}$ ) o que coincidiu com o período em que se intensificou a desidratação das sementes (Figura 2B), embora o percentual máximo de germinação (Figura $3 \mathrm{~A}$ ) tenha ocorrido antes do maior incremento de massa seca (Figura 2C). A partir dos 30 DAA houve pequeno decréscimo no percentual de germinação (Figura 3A), Costa et al. (2002), trabalhando com sementes híbridas de abóbora, constataram que, aos $50 \mathrm{DAA}$, apenas $15 \%$ das sementes germinaram chegando a $31 \%$ aos 60 DAA; diferente do presente trabalho, em que se obteve aos 15 DAA, germinação média de 49,95\%, percentual considerado alto quando comparado com os obtidos em outras cucurbitáceas. O valor mais próximo desse percentual de germinação foi obtido em sementes de melão $69 \%$ aos 27 DAA, conforme relatam Ribeiro et al. (2007).

Na primeira contagem de germinação, o mínimo foi de $42,45 \%$ aos 15 DAA e o máximo de $84,31 \%$ aos 32,2 DAA (Figura 3B). Comportamento similar foi observado em sementes de outras cucurbitáceas, sendo que a percentagem de germinação teve valores inferiores aos encontrados para sementes de maxixe. Em abóbora italiana, a primeira contagem de germinação foi mínima (23\%), em sementes de frutos colhidos aos 65 DAA, e máxima (63\%), em sementes de frutos colhidos aos 75 DAA (Alvarenga, et al., 1991). Em trabalho realizado com sementes híbridas de abóbora, a primeira contagem de germinação foi mínima (15\%) aos 50
DAA e máxima (54\%) aos 60 DAA (Costa et al., 2002).

No que diz respeito ao IVE, observa-se valor de 1,74 aos 15 DAA e 8,94 aos 40 DAA, com o máximo de 11,39 obtido aos 32,62 DAA (Figura 3C). Esses valores de IVE têm tendência semelhante aos de germinação (Figura 3A) e primeira contagem de germinação (Figura $3 \mathrm{~B}$ ), sugerindo que as sementes obtidas de frutos colhidos com esta idade já atingiram a maturidade fisiológica.

No teste de envelhecimento acelerado, observouse aumento na germinação durante praticamente todo o período avaliado com um ligeiro decréscimo no final do período (Figura 3D). A germinação aos 15 DAA foi de $25,34 \%$, e aos 40 DAA com 49,27\%, e o máximo aos 32,56 DAA com percentuais médios de $63,39 \%$, demonstrando alto potencial fisiológico. Comportamento semelhante foi observado nas variações de germinação (Figura 3A), primeira contagem de germinação (Figura $3 \mathrm{~B}$ ) e índice de velocidade de emergência (Figura $3 C$ ). Isso sugere que as sementes estão completamente formadas aos 32,56 DAA, por obter elevada percentagem de germinação após passar por um período de estresse no envelhecimento acelerado. Vidigal et al. (2006), com o uso do teste de envelhecimento acelerado, encontraram para sementes de tomate extraídas de frutos com 50 e 60 DAA, percentual de germinação de $86 \%$, bem mais alto do que as obtidas com sementes de maxixe.

Os valores obtidos para condutividade elétrica (Figura $3 \mathrm{E}$ ) indicam que inicialmente houve uma grande quantidade de lixiviados, decrescendo à medida que aumentaram os dias para a colheita dos frutos. A condutividade elétrica variou de 2321,57 $\mu \mathrm{S} . \mathrm{cm}^{-1} \cdot \mathrm{g}^{-1}$ em sementes com 15 DAA a 1556,19 $\mu \mathrm{S} . \mathrm{cm}^{-1} \cdot \mathrm{g}^{-1}$ aos $40 \mathrm{DAA}$, tendo permanecido decrescente, embora com menor intensidade a partir dos 30 DAA, indicando haver uma organização e maior integridade das membranas celulares por ocasião da colheita dos frutos. Em tomate, os valores de condutividade elétrica (CE) observados para as sementes extraídas de frutos com idade de 60 DAA indicavam que as sementes já estavam completamente formadas (Vidigal et al., 2006). Já em pepino, Nakada et al. (2008) obtiveram os melhores resultados em sementes colhidas aos 30 DAA, observando-se valores de $71 \mu{\mathrm{S} . \mathrm{cm}^{-}}^{-}$ ${ }^{1} \cdot \mathrm{g}^{-1}$ aos 30 DAA e $16 \mu \mathrm{S} . \mathrm{cm}^{-1} \cdot \mathrm{g}^{-1}$ aos 55 DAA. Esses resultados indicam que as sementes possuíam inicialmente um menor potencial fisiológico, liberando maior quantidade de lixiviados como conseqüência da menor estruturação e seletividade das membranas; posteriormente, houve uma redução na lixiviação de solutos em decorrência da estruturação adequada das membranas celulares com a aproximação do ponto de maturidade fisiológica. 

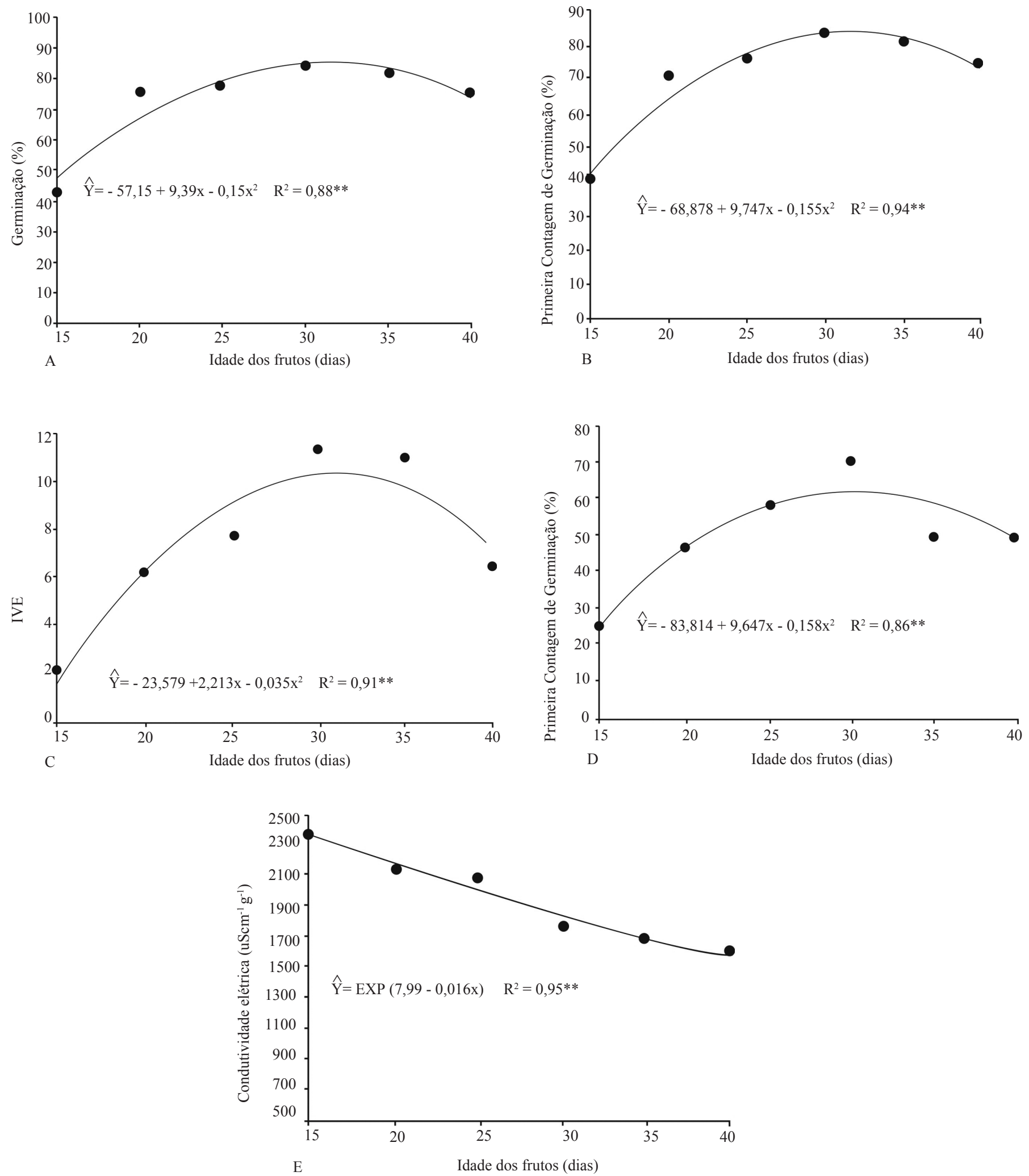

FIGURA 3. Germinação (A), primeira contagem de germinação (B), índice de velocidade de emergência (C), envelhecimento acelerado (D) e condutividade elétrica (E) de sementes de maxixe, cv Do Norte, em função da idade dos frutos. 
Comparando o aspecto externo dos frutos, a massa e o teor de água das sementes, com as demais características avaliadas, observou-se que aos 32 DAA o aumento significativo no conteúdo de massa seca e a redução do teor de água refletiram em aumento no vigor das sementes. Por outro lado, as análises demonstraram que as colheitas realizadas após este período, embora apresentem o maior conteúdo de massa seca acumulado pelas sementes não apresentou reflexos positivos no desempenho das mesmas.

\section{CONCLUSÕES}

As sementes de maxixe atingem a maturidade fisiológica em torno dos 32 DAA, embora a melhorépoca para a realização da colheita de frutos seja no período variando de 35 a 40 DAA, quando as sementes se encontram com menor teor de água. Nesse período os frutos se apresentam com coloração externa transitória do amarelado ao completamente amarelo, constatando elevada qualidade fisiológica das sementes.

\section{REFERÊNCIAS}

ALVARENGA, E.M.; SILVA, R.F.; ARAÚJO, E.F.; LEIRO, L.S. Maturação fisiológica de sementes de abóbora italiana. Revista Brasileira de Sementes, v.13, n.2, p.147150, 1991.

ASSOCIATION OF OFFICIAL SEED ANALYSTS. Seed vigor testing handbook. East Lasing: AOSA, 1983. 93p. (Contribution, 32).

BRASIL. Ministério da Agricultura e Reforma Agrária. Secretaria Nacional de Defesa Agropecuária. Departamento Nacional de Defesa Vegetal. Coordenação de Laboratório Vegetal. Regras para análise de sementes. Brasília, DF, 1992. 365p.

CARVALHO, N.M.; NAKAGAWA, J. Sementes: ciência, tecnologia e produção. 4.ed. Jaboticabal: FUNEP, 2000. $588 \mathrm{p}$.

COSTA, C.J.; NASCIMENTO, W.M.; CARMONA, R. Efeito da idade e do armazenamento dos frutos na qualidade fisiológica de sementes híbridas de abóbora. Horticultura Brasileira, v.20, n.2, 2002. Suplemento 2.

COSTA, C.J.; CARMONA, R.; NASCIMENTO, W.M. Idade e tempo de armazenamento de frutos e qualidade fisiológica de sementes de abóbora híbrida. Revista Brasileira de Sementes, v.28, n.1, p.127-132, 2006.
GIEHL， R.F.H.; FAGAN, E.B.; EISERMANN, A.C.; BRACKMANN, A.; MEDEIROS, S.P.; MANFRON, P.A. Crescimento e mudanças físico-químcias durante a maturação de frutos de meloeiro (Cucumis melo var. cantalupensis Naud.) híbrido Torreon. Ciência e Agrotecnologia, v.32, n.2, p.371-377, 2008.

GILLASPY, G.; BEM-DAVID, H.; GRUISSEM, W. Fruits: a developmental perspective. The Plant Cell, v.5, n.10, p.1439-1451, 1993.

GRANGEIRO, L.C.; MENDES, A.M.S.; NEGREIROS, M.Z.; SOUZA, J. O.; AZEVÊDO, P.E. Acúmulo e exportação de Nutrientes pela Cultivar de Melancia Mickylee. Revista Caatinga, v.18, n.2, p.73-81, 2005.

JANDEL SCIENTIFIC. Table curve: curve fitting software. Corte Madera, 280p. 1991.

MAGUIRE, J.D. Speeds of germination-aid selection and evaluation for seedling emergence and vigor. Crop Science, v.2, p.176-177, 1962.

MARCOS FILHO, J. Fisiologia de sementes de plantas cultivadas. Piracicaba: FEALQ, 495p. 2005.

MARCOS FILHO, J. Teste de envelhecimento acelerado. In: KRZYZANOWSKI, F.C.; VIEIRA, R.D.; FRANÇA NETO, J.B. (Ed.). Vigor de sementes: conceitos e testes. Londrina: ABRATES, 1999. p.1-24.

MEDEIROS, M.A. Acúmulo e exportação de nutrientes em abóbora butternut. 2006. 23f. Monografia (Graduação em Agronomia), Universidade Federal Rural do Semi-Árido, Mossoró, 2006.

NAkADA, P.G.; OLIVEIRA, J.A.; GOMES, L.A.A.; MELO, L.C.; SILVA, A.A. Estádios de maturação e secagem na qualidade fisiológica de sementes de pepino. In: CONGRESSO BRASILEIRO DE OLERICULTURA, 48., 2008, Maringá. Resumos... Maringá: ABH, 2008. p.20642070.

RIBEIIRO, M.C.C.; BENEDITO, C.P.; COSTA, A.A.; OLIVEIRA, G.L.; NUNES, T.A.; CARDOSO, A.A. Influência da idade dos frutos e do armazenamento na germinação de sementes de melão (Cucumis melo L.). Revista Brasileira de Biociências, v.5, supl.2, p.1113-1115, 2007.

TORRES, S.B.; CASEIRO, R.F.; RODO, A.B.; MARCOS FILHO, J. Testes de vigor em sementes de maxixe (Cucumis 
anguria L.) com ênfase ao teste de condutividade elétrica. Revista Brasileira de Sementes, v.20, n.2, p.241-244, 1998.

TORRES,S.B.;MARCOSFILHO,J.TestedeEnvelhecimento Acelerado em Sementes de Maxixe (Cucumis anguria L.). Revista Brasileira de Sementes, v.23, n.2, p.108-112, 2001.

VIDIGAL，D.S.; DIAS，D.C.F.S.; NAVEIRA，D.S.P.C.; ROCHA, F.B.; BHERING, M.C. Qualidade fisiológica de sementes de tomate em função da idade e do armazenamento pós-colheita dos frutos. Revista Brasileira de Sementes, v.28, n.3, p.87-93, 2006.

VIDIGAL, D.S.; DIAS, D.C.F.S.; PINHO, E.V.R.; DIAS, L.A.S. Alterações fisiológicas e enzimáticas durante a maturação de sementes de pimenta (Capsicum annuиm L.). Revista Brasileira de Sementes, v.31, n.2, v.37, p.129-136, 2009a.

VIDIGAL, D.S.; DIAS, D.C.F.S.; PINHO, E.V.R.; DIAS,
L.A.S. Sweet pepper seed quality and lea-protein activity in relation to fruit maturation and post-harvest storage. Seed Science and Technology, v.37, p.192-201, 2009b.

VIDIGAL, S.M.; PACHECO, D.D.; FACION, C.E. Crescimento e acúmulo de nutrientes pela abóbora híbrida tipo Tetsukabuto. Horticultura Brasileira, v.25, p.375-380, 2007.

VILLANUEVA, M.J.; TENORIO, M.D.; ESTEBAN, M.A.; MENDOZA, M.C. Compositional changes during ripening of two cultivars of muskmelon fruits. Food Chemistry, v.87, p.179-185, 2000.

WELBAUM, G.E; BRADFORD, K.J. Water relations of seeds development and germination in muskmelon (Cucumis melo L.). I. Water relations of seeds and fruit development. Plant Physiology, v.86, p.406-411, 1988. 